\title{
BIODEGRADABILITY AND MECHANICAL BEHAVIOUR OF SUGAR PALM STARCH BASED BIOPOLYMER
}

\author{
${ }^{1}$ J. Sahari, ${ }^{2,3,4}$ S.M. Sapuan, ${ }^{2,5}$ E.S. Zainudin and ${ }^{6}$ M.A. Maleque \\ ${ }^{1}$ Faculty of Science and Natural Resources, \\ Universiti Malaysia Sabah, Jalan UMS, 88400 Kota Kinabalu, Sabah, Malaysia \\ ${ }^{2}$ Department of Mechanical and Manufacturing Engineering, \\ ${ }^{3}$ Laboratory of Biocomposite Technology, Institute of Tropical Forestry and Forest Products (INTROP), \\ ${ }^{4}$ Aerospace Manufacturing Research Centre (AMRC), Faculty of Engineering, \\ Universiti Putra Malaysia, 43400 UPM Serdang, Selangor, Malaysia \\ ${ }^{5}$ School of Engineering and Design, Brunel University, Uxbridge Middlesex \\ UB8 3PH United Kingdom \\ ${ }^{6}$ Department of Manufacturing and Materials Engineering, \\ International Islamic University Malaysia, 53100 Kuala Lumpur, Malaysia
}

Received 2014-10-21; Revised 2014-10-30; Accepted 2014-11-08

Funding: This project is partly funded by Ministry of Agriculture and Agro-Based Industry, Malaysia

Competing Interests: The authors have declared that no competing interests exist

\begin{abstract}
A new Sugar Palm Starch (SPS) based biopolymer was successfully developed using glycerol as plasticizer. The effect of glycerol concentration (viz., 15, 20, 30 and 40 by weight percent) to the mechanical properties of plasticized SPS biopolymer was investigated. From this investigation, it was found that the $30 \%$ glycerol concentrated biopolymer showed the highest flexural strength and impact with the value of $0.13 \mathrm{MPa}$ and $6.13 \mathrm{~kJ} / \mathrm{m}^{2}$ respectively. Later, the above $30 \%$ glycerol biopolymer was undergone through weathering and biodegradation test. The biodegradability test showed $78.09 \%$ of tensile strength lost after $72 \mathrm{~h}$ of weathering testing period. Meanwhile, the weight loss (\%) of the same biopolymer was $63.58 \%$ after $72 \mathrm{~h}$ of biodegradation test.
\end{abstract}

Keywords: Biopolymer, Sugar Palm Starch, Mechanical Properties, Biodegradable, Bioresin

\section{INTRODUCTION}

The rising concern towards environmental issues has led to increase the interest of using polymer derived from renewable sources and those are biodegradable. Biopolymers have attracted an increasing amount of attention due to environmental concerns and the realization that petroleum resources are finite. The petroleum based polymers degrade and produces dangerous substances to the environment (Chandra and Rustgi, 1997). Therefore, it is important to minimize the volume of petroleum based polymer disposal which is responsible to the environment problem (Sahari et al., 2011).

Recent trend in the packaging industry is to design and development of new material using natural resources. This new generation biobased product becoming a vital alternative to reduce the dependency on petroleum based materials. One of the most important material that can be developed for packaging and consumer application is starch as a biopolymer. It is a well known polymer with the advantages of

Manufacturing Engineering, Universiti Putra Malaysia, 43400 UPM Serdang, Selangor, Malaysia Tel: +603 89471788; Fax: +603 89471896 
biodegradable, renewable, inexpensive, abundant and lightweight (Sahari and Sapuan, 2012). The starch is not a real polymers, but, it will behave as synthetic polymer in the presence of a plasticizer such as water and glycerol at high temperature (Garcia et al., 2000). Sugar palm tree contain of starch in its trunk which can be used as a biopolymer. No previous research have been done on development of biopolymer derived from SPS; however, with the fact, that it has been widely done and documented with many other plants (Vilaseca et al., 2007; Hermann et al., 1998; Bastioli, 1998). This study complements and expands a previous publication (Sahari et al., 2012; 2013), which focus on the addition analysis of mechanical properties (i.e., flexural and impact), effect of weathering test and biodegradation of biopolymer derived from SPS.

\section{MATERIALS AND METHOD}

\subsection{Preparation of Sugar Palm Starch}

The matured sugar palm tree located at Jempol, Negeri Sembilan, Malaysia was felled using chainsaw and the mixture of woody fibres and starch powder was collected from the inner part of the stem. Then the mixture was washed off with water, whereby the starch settles at the bottom and the excess water flows over the sides. After washing process, the wet starch was taken out from the container and dried in oven at $120^{\circ} \mathrm{C}$ for 24 $\mathrm{h}$ to remove the water.

\subsection{Fabrication of SPS Biopolymer}

SPS biopolymer was successfully prepared by using glycerol with a specific ratio of $15 \mathrm{w} / \mathrm{w} \%$ (SPS/G15), 20 w/w\% (SPS/G20), 30 w/w\% (SPS/G30) and $40 \mathrm{w} / \mathrm{w} \%$ (SPS/G40). The mixture was stirred for $30 \mathrm{~min}$ at $40^{\circ} \mathrm{C}$ followed by casting in an iron die for curing process. The mixture was compacted with Carver hydraulic hot press under the load of 10 tonne at $130^{\circ} \mathrm{C}$ for $30 \mathrm{~min}$.

\subsection{Mechanical Testing of SPS Biopolymer}

Flexural tests were conducted using Instron 3365 machine, according to ASTM D790. Impact strength was measured by 43-02-01 Monitor Impact Tester, according to ASTM D 256.

\subsection{Weathering Test}

The weathering test was done by using Q-Sun Xenon arc weathering chamber at Polymers Technology Group,
SIRIM Berhad, Malaysia. The weathering test was performed according to ASTM G155 for $72 \mathrm{~h}$. The average temperature used was $28^{\circ} \mathrm{C}$ while the average relative humidity was $82 \%$.

\subsection{Biodegradability Test}

Biodegradability test of biopolymer was performed after buried the specimens in compost soil. Triplicate specimens $(30 \times 10 \mathrm{~mm})$ of SPS/G30 were buried 100 $\mathrm{mm}$ beneath from the surface of soil under moisture controlled conditions (regularly moistened with distilled water). The specimens were dug out from the compost soil after 24, 48 and $72 \mathrm{~h}$. The compost specimen was then washed off with water followed by drying in an oven at $60^{\circ} \mathrm{C}$. Finally, the weight loss was measured using the equation below:

$$
\text { Weight loss }(\%)=\frac{W_{0}-W_{t}}{W_{0}} \times 100
$$

Where:

$W_{0}=$ weight before buried

$W_{t}=$ weight after buried

\subsection{Scanning Electron Microscopy (SEM)}

The fracture surfaces of the unweathered and weathering tested of SPS/G30 were examined by a Scanning Electron Microscopy (SEM) Hitachi S-3400N operating at an acceleration voltage of $0.3-30 \mathrm{kV}$.

\section{RESULTS AND DISCUSSION}

\subsection{Mechanical Properties}

Table 1 shows the mechanical properties of plasticized SPS biopolymer. It was revealed that SPS/G30 shows the higher flexural strength and flexural modulus with the value of $0.13( \pm 0.013) \mathrm{MPa}$ and 87.54 $( \pm 5.6) \mathrm{MPa}$ respectively. However, the impact strength improves with the increasing of glycerol up to $30 \%$ with the value of $6.13( \pm 0.325) \mathrm{kJ} / \mathrm{m}^{2}$. Similar trend was observed for the tensile strength which shows that the higher the concentration of the plasticizers, the higher the tensile strength of plasticized SPS and hence, optimum concentration of glycerol for the biopolymer was $30 \mathrm{wt} \%$. The increasing of plasticizer content in starch will interfere with the arrangement of the polymer chains and the hydrogen bonding (Sahari et al., 2013). It is most likely affect the crystallinity of starch by 
decrease the polymer interaction and its glass transition temperature (Laohakunjit and Noomhorm, 2004). Thus, the increasing of glycerol make the plasticized SPS become more flexible.

\subsection{Effect of Weathering Test on Tensile Strength}

Figure 1 shows the tensile strength of SPS/G30 after weathering test at different time. It was found that the tensile strength of SPS/G30 was decrease significantly from $2.42 \pm 0.07$ to $0.53 \pm 0.054 \mathrm{MPa}$ (i.e., $78.09 \%$ ) after $72 \mathrm{~h}$. This can be attributed to the degradation of starch by UV radiation (Bertolini et al., 2001). Weathering test is a process of degradation properties of polymer due to UV radiation, moisture, oxygen, etc. Wan et al. (2009) claimed that UV radiation will causes oxidative degradation of the polymer in the presence of oxygen. It can change the chemical cross linking or chain scission of the polymeric material.

\subsection{Biodegradable Properties}

The weight loss of SPS/G30 after biodegradation test was also shown in Fig. 2. The SPS/G30 lost $63.58 \%$ weight after buried for $72 \mathrm{~h}$. The weight loss of SPS/G30 can be attributed to the hydrophilic behaviours of starch which allow more chance to microorganism attack. This is likely to allow microorganisms, such as bacteria and fungi, access to the bottom side of the SPS/G30 using water as a medium; the result implies that the samples with higher starch contents would exhibit the potential for better biodegradability (Kiatkamjornwong et al., 1999). The microorganisms will produce enzymes when contact with the biodegradable polymer. The enzymes then break down the polymers into a smaller chains and lower average molecular weights (Bonhomme et al., 2003). It can be seen that SPS/G30 degrades very quickly in soil as observed by naked eye. Shubhra et al. (2011) claimed that mechanical damage in soil is caused by the activities of microorganism.

\subsection{Surface Morphology}

Figure 3 shows the morphological surfaces of SPS/G30 after tensile test. It can be seen that large cracks appear on the surface of the SPS/G30 due to weathering test. This cracks apparently resulted in its collapse, thus lowering the tensile strength of SPS/G30.

Table 1. Mechanical properties of polymerized SPS

\begin{tabular}{llllll}
\hline Mechanical properties & SPS/G15 & SPS/G20 & SPS/G30 & SPS/G40 & References \\
\hline Flexural strength (MPa) & $0.06( \pm 0.011)$ & $0.11( \pm 0.01)$ & $0.13( \pm 0.013)$ & $0.04( \pm 0.018)$ & Current study \\
Flexural modulus $(\mathrm{MPa})$ & $24.71( \pm 2.3)$ & $76.12( \pm 3.4)$ & $87.54( \pm 5.6)$ & $18.06( \pm 3.3)$ & Current study \\
Impact strength $\left(\mathrm{kJ} / \mathrm{m}^{2}\right)$ & $2.6( \pm 0.212)$ & $3.42( \pm 0.271)$ & $6.13( \pm 0.325)$ & $4.12( \pm 0.333)$ & Current study \\
Tensile strength $(\mathrm{MPa})$ & $0.51( \pm 0.03)$ & $1.25( \pm 0.12)$ & $2.42( \pm 0.07)$ & $0.5( \pm 0.11)$ & (Sahari et al., 2013) \\
\hline
\end{tabular}

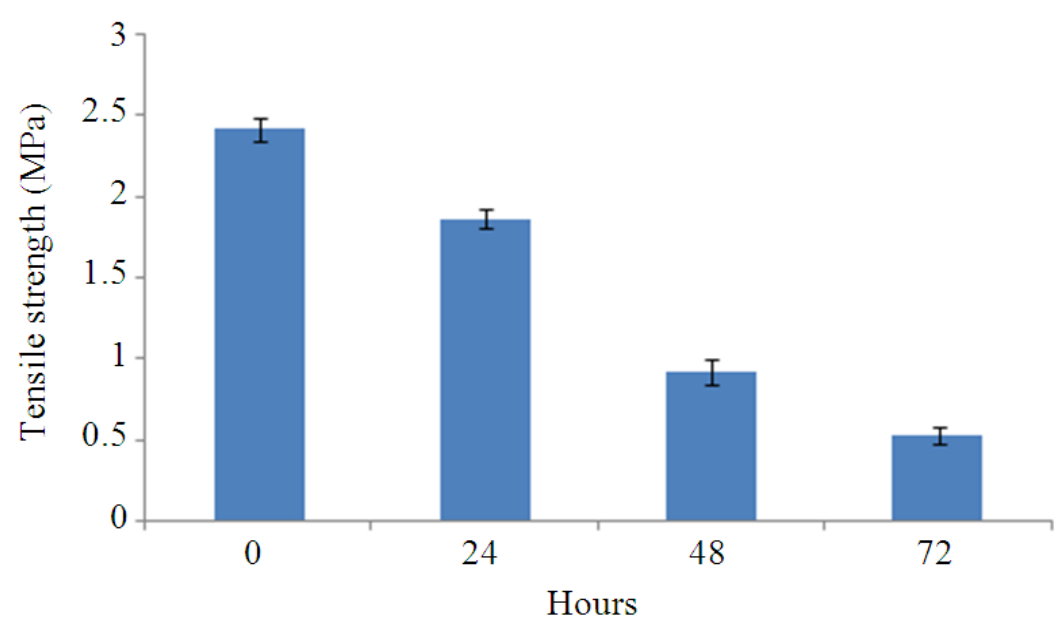

Fig. 1. Tensile strength of SPS/G30 after weathering test 


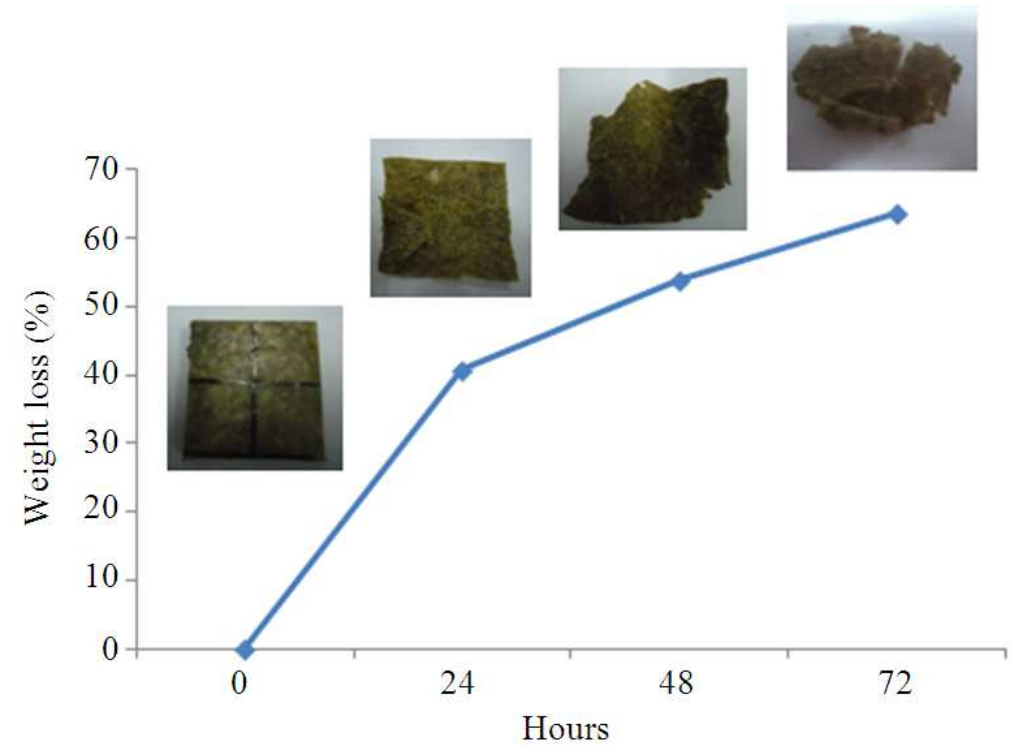

Fig. 2. Weight loss of SPS/G30 after soil burial
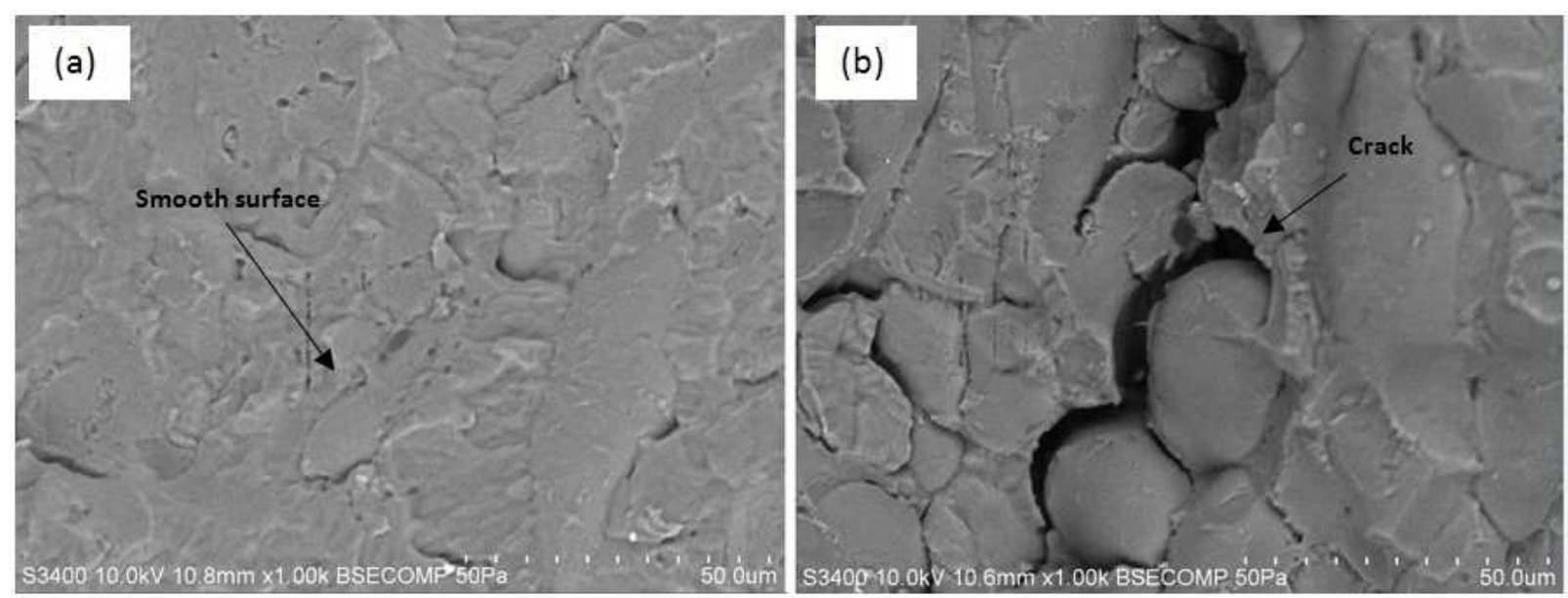

Fig. 3. SEM images of SPS/G30 after tensile test (a) unweathered (b) $72 \mathrm{~h}$ weathering

\section{CONCLUSION}

A new on sugar palm starch based biopolymer was developed successfully. The effect of glycerol concentration on the flexural and impact properties of plasticized SPS was investigated. From the investigation, it was found that the SPS/G30 biopolymer showed the highest flexural strength and impact strength compared to other glycerol concentration. For the weathering test analysis, it was found that the SPS/G30 was lost $78.09 \%$ of tensile strength at the end of $72 \mathrm{~h}$. Meanwhile, SPS/G30 biopolymer degrades with the weight loss of $63.58 \%$ after $72 \mathrm{~h}$ of biodegradation test.

\section{ACKNOLEDGEMENT}

The researchers are grateful for the financial supports from Ministry of Higher Education under the 10th Malaysia Plan via the MyBrain 15 program and to Universiti Malaysia Sabah for their facilities and support during the research that has been conducted. 


\section{ADDITIONAL INFORMATION}

\subsection{Funding Information}

This project is partly funded by Ministry of Agriculture and Agro-Based Industry, Malaysia

\subsection{Author's Contributions}

Sahari, J.: The principal author of the paper and this work is part of his $\mathrm{PhD}$ thesis at Universiti Putra Malaysia.

Sapuan, S.M.: The corresponding author of the paper and the Chairman of the Supervisory Committee of PhD studies of Sahari J.

Zainudin, E.S.: The member of the supervisory Committee of PhD studies of Sahari J.

Maleque, M.A.: The member of the Supervisory Committee of PhD studies of Sahari J.

\subsection{Ethics}

No ethical issues that may arise after the publication of this article.

\section{REFERENCES}

Bastioli, C., 1998. Biodegradable materials-present situation and future perspectives. Macromolecular Symposia, 130: 379-204. DOI: 10.1002/masy.19981350122

Bertolini, A.C., C. Mestres, P. Colonna and J. Raffi, 2001. Free radical formation in UV- and gamma-irradiated cassava starch. Carbohydrate Polymers, 44: 269-271. DOI: 10.1016/S0144-8617(00)00268-X

Bonhomme, S., A. Cuer, A.M. Delort, J. Lemaire and M. Sancelme et al., 2003. Environmental biodegradation of polyethylene. Polymer Degradat. Stability, 81: 441-452. DOI: 10.1016/S0141-3910(03)00129-0

Chandra, R. and R. Rustgi, 1997. Biodegradation of maleated linear low-density polyethylene and starch blends. Polymer Degradat. Stability, 56: 185-202. DOI: 10.1016/S0141-3910(96)00212-1

Garcia, M.A., M.N. Martino and N.E. Zaritzky, 2000. Microstructural characterization of plasticized starch-based films. Starch Stärke, 52: 118-124. DOI: 10.1002/1521-379X(200006)52:4<118::AIDSTAR118>3.0.CO;2-0

Hermann, A.S., J. Nickel and U. Riedel, 1998. Construction materials based upon biologically renewable resources-from components to finished parts. Polymer Degradat. Stability, 59: 251261. DOI: $10.1016 /$ S0141-3910(97)00169-9
Kiatkamjornwong, S., M. Sonsuk, S. Wittayapichet, P. Prasassarakich and P.C. Vejjanukroh, 1999. Degradation of styrene-g-cassava starch filled polystyrene plastics. Polymer Degradat. Stability, 66: 323-335. DOI: 10.1016/S0141-3910(99)00082-8

Laohakunjit, N. and A. Noomhorm, 2004. Effect of plasticizers on mechanical and barrier properties of rice starch film. Starch Stärke, 56: 348-356. DOI: 10.1002/star.200300249

Sahari, J., S.M. Sapuan, Z.N. Ismarrubie and M.Z.A. Rahman, 2011. Investigation on bending strength and stiffness of sugar palm fibre from different parts reinforced unsaturated polyester composites. Key Eng. Materials, 471: 502-506. DOI: 10.4028/www.scientific.net/KEM.471-472.502

Sahari, J., S.M. Sapuan, E.S. Zainudin and M.A. Maleque, 2012. A new approach to use Arenga pinnata as sustainable biopolymer: Effects of plasticizers on physical properties. Procedia Chem., 4: 254-259. DOI: 10.1016/j.proche.2012.06.035

Sahari, J. and S.M. Sapuan, 2012. Natural fibre reinforced biodegradable polymer composites. Rev. Adv. Materials Sci., 30: 166-174.

Sahari, J., S.M. Sapuan, E.S. Zainudin and M.A. Maleque, 2013. Thermo-mechanical behaviors of thermoplastic starch derived from sugar palm tree (Arenga pinnata). Carbohydrate Polymers, 92: 1711-1716. DOI: 10.1016/j.carbpol.2012.11.031

Shubhra, Q.T.H., A.K.M.M. Alam and M.D.H. Beg, 2011. Mechanical and degradation characteristics of natural silk fiber reinforced gelatin composites. Materials Lett., 65: 333-336. DOI: 10.1016/j.matlet.2010.09.059

Vilaseca, F., J.A. Mendez, A. Pelach, M. Llop and N. Canigueral et al., 2007. Composite materials derived from biodegradable starch polymer and jute strands. Process Biochem., 42: 329-334. DOI: 10.1016/j.procbio.2006.09.004

Wan, Y.Z., H. Luo, F. He, H. Liang and Y. Huang et al., 2009. Mechanical, moisture absorption and biodegradation behaviours of bacterial cellulose fibre-reinforced starch biocomposites. Compos. Sci. Technol., 69: 1212-1217. DOI: 10.1016/j.compscitech.2009.02.024 